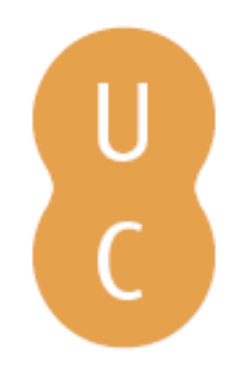

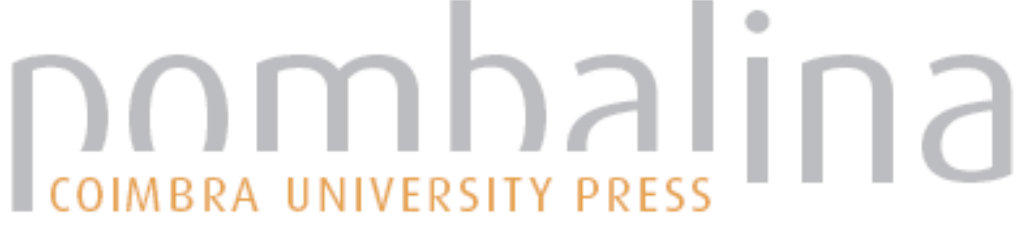

\section{A complexidade e o conhecimento nos séculos XIII e XX: uma reflexão epistemológica}

\author{
Autor(es): $\quad$ Saldanha, Gustavo Silva \\ Publicado por: Imprensa da Universidade de Coimbra \\ URL \\ persistente: URI:http://hdl.handle.net/10316.2/31863 \\ DOI: $\quad$ DOI:http://dx.doi.org/10.14195/978-989-26-0319-3_8 \\ Accessed : $\quad$ 26-Apr-2023 11:26:47
}

A navegação consulta e descarregamento dos títulos inseridos nas Bibliotecas Digitais UC Digitalis, UC Pombalina e UC Impactum, pressupõem a aceitação plena e sem reservas dos Termos e Condições de Uso destas Bibliotecas Digitais, disponíveis em https://digitalis.uc.pt/pt-pt/termos.

Conforme exposto nos referidos Termos e Condições de Uso, o descarregamento de títulos de acesso restrito requer uma licença válida de autorização devendo o utilizador aceder ao(s) documento(s) a partir de um endereço de IP da instituição detentora da supramencionada licença.

Ao utilizador é apenas permitido o descarregamento para uso pessoal, pelo que o emprego do(s) título(s) descarregado(s) para outro fim, designadamente comercial, carece de autorização do respetivo autor ou editor da obra.

Na medida em que todas as obras da UC Digitalis se encontram protegidas pelo Código do Direito de Autor e Direitos Conexos e demais legislação aplicável, toda a cópia, parcial ou total, deste documento, nos casos em que é legalmente admitida, deverá conter ou fazer-se acompanhar por este aviso.

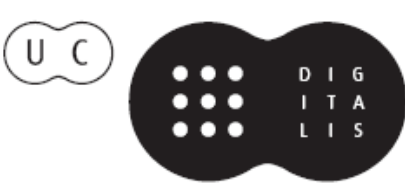


Maria Manuel Borges

Elias Sanz Casado

Coordenação

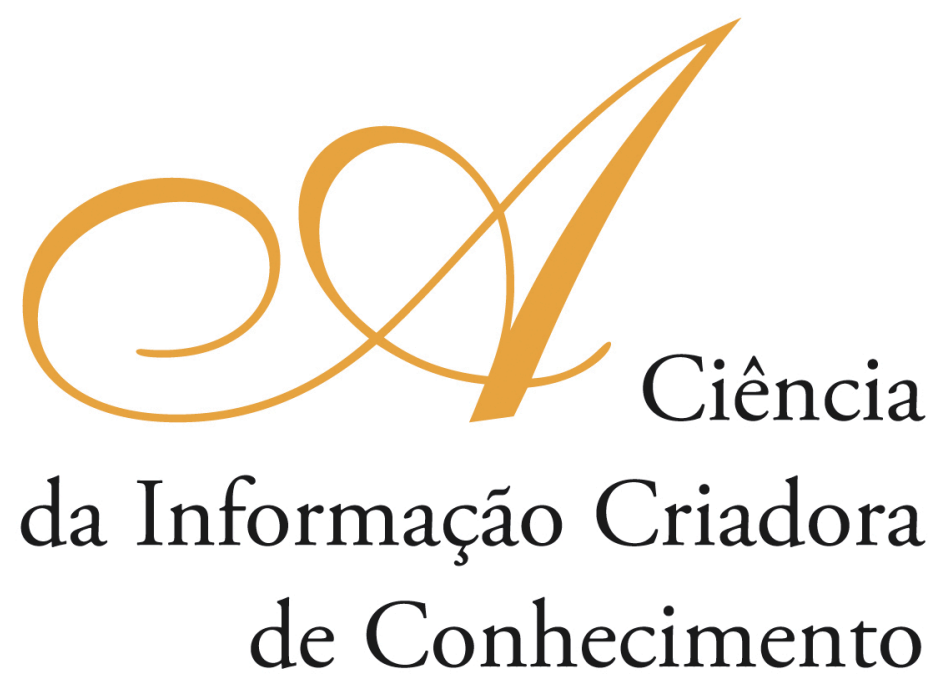

Vol. I

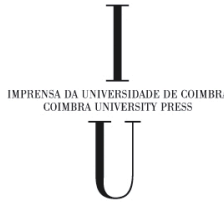

- COIMBRA 2009 


\title{
A Complexidade e o CONHecimento nos séculos XIII e XX: UMA REFLEXÃo EPISTEMOLÓGICA
}

\author{
Gustavo Silva Saldanha \\ Fundaçâo Biblioteca Nacional (Brasil) \\ Instituto Brasileiro de Informaçáo em Ciência e Tecnologia, Ministério de Ciência e Tecnologia \\ (Brasi)l
}

\section{Resumo}

A complexidade como categoria de análise ganha evidência nos gestos discursivos contemporâneos. O século XX retoma investigaçóes em torno da multiplicidade dos itinerários existentes para realizaçáo da viagem ao conhecimento e da presença de ângulos alternativos de contemplaçáo do livro do mundo. No entanto, a cartografia epistemológica apresenta características singulares na apropriação dos conceitos do complexo e do conhecer entre o antes e o depois daquela que ficou conhecida como fase de especialização e isolamento das disciplinas na modernidade, fase intermediária esta marcada pela ascensão do pensamento positivista, fundamentalmente pela presença de August Comte e Emile Durkheim na paisagem científica. Se em um período remoto, medieval, o acesso ao conhecimento pela via da complexidade teria ocorrido a partir das narrativas, por outro lado, nos tempos recentes, o conhecer ligado ao complexo se faria pela via da informação. Se, na Idade Média, as práticas do ensino e da aprendizagem conviviam com o imaginário povoado pela presença do maravilhoso no cotidiano, como na conceituação de Jacques Le Goff, noção imersa na intersubjetividade dos discursos narrativos, na esfera temporal do século passado a informação substituiria, após um possível esgotamento da modernidade, o sublime no cotidiano como possibilidade de acesso ao saber, no intuito de afastar o contato com o maravilhoso, este tomado como ruído prejudicial à viagem ao livro do mundo. No entanto, em contrapartida, a informação terminaria por se tornar o maravilhoso na chamada pós-modernidade, na medida que tende a aproximar, através das tecnologias da comunicação, diferentes sociedades em torno de um imaginário que consagra a mensagem midiática como essência da aprendizagem e único caminho para a aquisição de saberes. A análise a partir de uma história comparada entre os séculos XIII e XX contribui para o esclarecimento destas condiçóes. Ambos os períodos refletem momentos de profundas transformaçôes sociais orientadas por movimentaçôes sensíveis no estatuto epistemológico das instituiçôes de ensino. Propomos como metodologia de investigaçáo um estudo hermenêutico das noçóes de complexidade e de conhecimento entre os períodos mencionados. Nosso campo empírico posiciona-se em torno de dois indícios da formaçáo discursiva de uma teoria do conhecimento ligados aos períodos históricos determinados: uma filosofia do conhecimento na Idade Média, explicitada nas práticas das primeiras universidades que florescem no século XII, e uma filosofia da informaçáo hodierna, que se desenvolve na atualidade na epistemologia da Ciência da Informação. O estudo permite tocar indícios que contribuem para a compreensão das causas da retomada do pensamento complexo na contemporaneidade. Do mesmo modo, a análise ilumina as estacas sobre a qual se sustentam os conceitos de conhecimento como utilizados naquela e nesta sociedade. Por fim, o trabalho conduz até um olhar crítico sobre certas classificaçóes consagradas, como a idéia de Idade Média como período sombrio ao conhecer e apenas fundamentado na noção de acesso ao conhecimento pela narrativa, e a pós-modernidade como etapa histórica promotora do conhecer, dependente tão somente da informação para a apreensão dos saberes. 


\begin{abstract}
The complexity gets evidence in discurse contemporary. The twentieth century revival investigations around the multiplicity the journey to knowledge and the presence of alternative angles from the contemplation of the book world. However, the mapping epistemological presents unique characteristics in the ownership of the complexity and known in the stage marked to the specialization and isolation of disiciplines in modernity. If in medieval period the access to knowledge through complex have occurred from the narratives, in recent times the access would be through information. In, in the Middle Ages, the practes of teaching and learning together with the "wonderful", as the concept of Jacques Le Goff, notion immersed in intersubjectivity, in past century, after a exhaustion of the modernity, the information would over the narrative in the contemporary age. However, in constrast, the information ended by becoming the "wonderful" in the post-modernity, in the communication technologies, round up different societies around an imaginary wich the media message how the essential way of learning e acquire of knowledge. The analysis from a comparative history between centuries XIII and XX contributed to the clarification of these conditions. Both periods reflect profound social changes in epistemological scheme. We propose a research methodology a hermeneutic study of the concepts of complexity and knowledge between the periods. Our empirical field are two discursive evidence of the formation of a theory of knowledge related to certain historical periods: a philosophy of knowledge in the Middle Ages e present philosophy of information, currently in the epistemology of Information Science. The study provides evidence that contributes to the understanding of the causes of the resumption of complex thought in contemporary. Similarly, the analysis illuminates the stakes on which underpin the concepts of knowledge in this society. Finally, the work leads to a critical look at certain classifications used, as the idea of the Middle Ages known as the dark period and only based on the concept of access to knowledge by the narrative, and post-modernity as a historical step promoter of it, dependent only the information for the apprehension of knowledge.
\end{abstract}

\title{
1. Introdução
}

A complexidade como categoria de análise ganha evidência nos gestos discursivos contemporâneos. O século XX retoma investigaçóes em torno da multiplicidade dos itinerários existentes para realização da viagem ao conhecimento e da presença de ângulos alternativos de contemplaçáo do livro do mundo. Cabe-nos perguntar o que significa o "complexo" e o "conhecimento" no cotidiano contemporâneo. Se em um período remoto, medieval, o acesso ao conhecimento pela via da complexidade teria ocorrido a partir das narrativas, por outro lado, nos tempos recentes, o conhecer ligado ao complexo se faria pela via da informação. Se, na Idade Média, as práticas do ensino e da aprendizagem conviviam com o imaginário povoado pela presença do maravilhoso no cotidiano, como na conceituação de Jacques Le Goff, noção imersa na intersubjetividade dos discursos narrativos, na esfera temporal do século passado a informação substituiria, após um possível esgotamento da modernidade, a narrativa no cotidiano como possibilidade de acesso ao saber, no intuito de afastar o contato com o maravilhoso, este tomado como ruído prejudicial à viagem ao livro do mundo segundo uma visão de mundo positivista.

No entanto, a informação terminaria por se tornar o maravilhoso na chamada pós-modernidade, na medida que tenderia a aproximar, através das tecnologias da 
comunicação, diferentes sociedades em torno de um imaginário que consagra - ou "fetichiza" - a mensagem midiática como essência da aprendizagem e único caminho para a aquisição de saberes. A análise a partir de uma história comparada entre os séculos XIII e XX contribui para o esclarecimento destas condições. Ambos os períodos refletem momentos de profundas transformaçôes sociais orientadas por movimentaçóes sensíveis no estatuto epistemológico das instituiçóes de ensino.

\section{As "explosóes informacionais" e o estatuto do conhecimento e da complexidade nos regimes epistemológicos da organizaçáo do saberes}

De um modo geral, tendo como ponto de partida a emergência dos estudos e práticas da organização do saberes, podemos reconhecer que a Ciência da Informação sobrevive sob a instauração de crises intermitentes na produção e distribuição de manifestaçóes cumulativas de uma cultura material. Assim como os desdobramentos da circulação de idéias no século XIII provocam a urgência de uma "industrialização" no processo de registro dos saberes, "levando" à invenção da imprensa, o fato histórico desdobrado deságua, por sua vez, na evidência de novas idéias, conduzindo à institucionalização da Biblioteconomia no século XIX. Em outras palavras, as crises nos regimes epistemológicos, provocando evidências da complexidade, são fenômenos propulsores de transformaçóes teóricas no campo.

Do mesmo modo, a hiper-especialização dos ramos do conhecimento, leva à necessidade de novos serviços e produtos no campo da informação científica e especializada, provocando a transformação nos meios - o que "daria origem" à transmissão de sinais -, que por sua vez provocaria a definição, a partir da plataforma epistemológica biblioteconômica, da institucionalização do discurso de uma Ciência da Informação. Desta forma, a complexidade envolve no campo a espiral da dinâmica de a) circulação de idéias, b) construção de canais para fixação, armazenamento e transmissão e c) formação/formalização de uma cultura discursiva de assimilaçáo em torno destas idéias, tendo os regimes epistemológicos do campo fortes oscilaçóes quando diante do aprofundamento de uma destas três instâncias.

Tomando como ponto de referência não apenas os objetos - os documentos -, as mídias - os meios -, mas também os potenciais receptores, intérpretes, permitimo-nos um olhar crítico sobre a definição da "explosão" pelo fato singular, porém unilateral, da produção de registros dos saberes. Os discursos que apontaram como fenômeno determinada multiplicação de registros, os olhares verdadeiramente potenciais que se interessam para estes objetos, os modos de divulgação, controle e recepção, todas estas instâncias nos levam a rever minuciosamente as contingências de uma "explosão informacional”. Em outras palavras, em um ponto de vista sociológico, tais ponderaçóes nos fariam perguntar: "explosão informacional" para quem?

Em seu discurso historiográfico e epistemológico, podemos indicar, a princípio, que a Ciência da Informação é fruto de uma passagem das ciências documentais à ciência da informação, como podemos trabalhar a partir do título da obra de Armando Malheiros da Silva e Fernanda Ribeiro (Silva, Ribeiro, 2002). No entanto, a possível "retomada" do documento a partir dos anos 1990 até os dias atuais como objeto da Ciência da Informação, como em Frohmann (1999), nos faz perceber que, ao contrário 
de uma passagem, a área é apenas uma, ou seja, seu conhecer se baseia na espiral que gira em torno da organização dos saberes.

Isto se dá porque, ao tratar da informação, a Ciência da Informação trata fundamentalmente da informação registrada. A partir desta, ela trabalha com todas as nuances, principalmente a partir do esclarecimento de Borko, em 1968, que podem levar os saberes até seu registro, aproximando-se assim de uma possível informação "não registrada", mas desde que também transmissível, ou seja, capaz de ser transmitida por algum canal que a "materialize" - donde se originaráo os enfoques cognitivos e pragmatistas do campo. Exatamente por isto, a oscilaçáo no regime epistemológico da virada dos séculos XIX para XX é tratada como "explosão informacional” - e esta, como semente da Ciência da Informação. A idéia histórica do livro - este, por mais de um milênio livre de sua expressão paradigmática conferida por Gutenberg, que lhe conferiu as características as quais atualmente confundimos a raiz "biblion" - esteve ligada a tudo aquilo que guarda e transmite conhecimento. Recuperada por Paul Otlet, porém sob outro termo, documento, esta noção será, segundo diferentes autores, como observam os pesquisadores portugueses Silva \& Ribeiro (2002), um dos pontos fundamentais para a identificaçáo da emergência do positivismo no campo, o que levaria a construção do neologismo "ciência da informação". A partir de então, os estudiosos do campo passariam a adotar outro significante, a informação, integrando os estudos voltados para organização dos saberes a diferentes fronteiras que tomavam o termo informação como objeto.

Os resultados desta adoção não alteram, no entanto, a compreensão de que, no campo, estamos voltados para o ideal permanente de organizar os saberes, visando sua preservação, representação e transmissão, fundamentos epistemológicos da Biblioteconomia deweyana, da Documentação otletiana e da Ciência da Informação borkiana, áreas indissociáveis em suas expressôes filosóficas. Porém, ao tratar, nos estudos contemporâneos, as questóes inerentes à complexidade e às formas de chegar ao conhecimento, o campo tende a compreender apenas a noção de informaçáo, a partir da tradição recente, como aquilo que é capaz de levar ao conhecer, e, simultaneamente, esta informação, como produtora e difusora da complexidade.

Cabe-nos analisar criticamente estes postulados. Discutindo a seguir, de forma concisa e panorâmica, a idéia de uma filosofia do conhecimento no século XIII e uma filosofia da informação no século XX, procuramos desconstruir as abordagens que, em geral, postulam a complexidade como categoria contemporânea, e o conhecimento como oriundo da informaçáo, de modo a perceber o fenômeno não apenas pelo seu caráter "científico", "objetivo", mas também por suas contradiçôes e silêncios.

\subsection{A explosão informacional no século XIII: a filosofia do conhecimento...}

A partir da primeira cruzada, de 1095, comandada por Urbano II, identificamos a consolidação de diferentes rotas econômicas. Neste processo, inicia-se um período de rápida urbanização, ganhando destaque cidades do mediterrâneo e dos países baixos. Inclui-se nesta movimentação histórica a renovação da administração das cidades, que passa para a mão de leigos (Saranyana, 2006, p. 175). O século XII será tratado, após as transformaçóes do século anterior, como século do Renascimento, antecipando assim 
as inferências em geral elevadas aos séculos XV e XVI. Instituição mais característica da Idade Média, a universidade chegaria até os dias atuais praticamente sem mudanças substanciais. Como afirmará Boni (2000), esta condição justificaria a afirmação de que nossas formas de saber contemporâneas têm sua origem nestas instituiçóes de quase mil anos. Perceberemos aqui a rápida passagem das escolas monásticas para as escolas catedrais e destas para o que hoje conceituamos de universidades. (Verger, 2001)

Os séculos XII e XIII seriam sinônimo de um princípio de liberdade para emergentes classes sociais - principalmente, uma classe que posteriormente seria conhecia como de "pesquisadores" - e de uma ampla valorização dos saberes pelos saberes - ou seja, do conhecimento pelo seu conteúdo histórico-cultural, náo apenas por sua carga ideológica, por seu senso comum ou ainda por sua condição de estrutura maravilhosa, capaz de refletir no homem segurança e prazer segundo uma iluminação divina. Devido aos trabalhos de tradução de Boécio, desde o século VI a cristandade tinha acesso a parte da obra de Aristóteles. A partir do século XII, um outro conjunto de obras do filósofo grego é traduzido, somado aos trabalhos de comentaristas, como Avicena, permitindo assim uma leitura profunda do pensamento aristotélico. A filosofia aristotélica contradizia, no entanto, o modelo de pensamento cristão de cunho profundamente platonista. Esta filosofia aristotélica posicionava Deus como motor, náo como criador - o conhecer a partir da complexidade das coisas sensíveis, as manifestaçóes compostas. O fato cultural de ter Aristóteles sido traduzido fundamentalmente por árabes definiria outro aspecto sócio-cultural: o filósofo viria de mãos pagãs. (SARANYANA, 2006, p. 263)

O conhecer e o complexo nas práticas de ensino do século XIII se pautariam fundamentalmente na sapiência do mestre e no saber pelo saber - este, por sua vez, estava nos livros, ou documentos, ou informaçóes históricas registradas a partir de traduçôes dos mestres e doutores da época, que circulavam entre as camadas de alunos cada vez mais amplas. Como destaca Verger (2000, p19), uma das marcas do século XIII será o crescimento "na produção de livros à disposição dos estudantes". Ou seja, "graças às novas traduçóes e às sumas redigidas pelos mestres de Paris e Bolonha, a quantidade de saberes disponível aumentou”. Neste período houve a passagem da escrita contínua para a escrita com palavras separadas, dando início à leitura silenciosa. Com a escolástica, impóe-se o texto livro, que influenciaria diretamente o cotidiano do medievo. Os indivíduos iniciavam seu contato com documentos escritos para os mais diversos fins, como testamentos, escrituras de propriedades, compras e vendas, atos públicos, instituiçóes privadas. (Ghisalberti, 2001)

No entanto, em diferentes olhares, traduzidos na Ciência da Informação quando da identificação da chamada "sociedade da informação", o período do medievo é localizado como ambiente fundamentalmente marcado pela transmissão do conhecimento pela oralidade. Em outras palavras, as narrativas representam a forma de acesso ao conhecimento. A ruptura com a Idade Moderna e, em seqüência, o mundo pós-moderno, estaria marcada, como nos olhares de Foucault (2002), Benjamin (1985) e Chartier (2001), pela substituição da narrativa pela informação. Objetiva, a informação responderia por uma visão de mundo positiva da realidade - em outros termos, uma visão de mundo "científica" -, enquanto a narrativa, confundida com a transmissão dos contos maravilhosos, lendas e mitos, seria identificada como senso comum. 


\subsection{As recentes "explosôes informacionais": o século XX e filosofia da informaçáo...}

A primeira característica no mundo do século XX é a ausência de filosofia. A “explosão informacional” é revelada primeiramente a partir de uma visão fisicalista: “explosão da informação" diz respeito à velocidade e quantidade, não à conteúdo - e muito menos à recepção. Em outras palavras, o enfoque aqui está mais na relação entre informação registrada e canais de fluxo de informação, e menos na relação entre estes e seus potenciais intérpretes. Um paradigma do acesso parece determinar os fundamentos epistemológicos sobre os quais se pauta o conhecer no século XX. Assim, quando falamos de uma filosofia da informação, definida no âmbito epistemológico da Ciência da Informação a partir dos anos 1960, tratamos essencialmente de um olhar pautado na revolução dos meios de comunicação e em sua capacidade de transformar as relaçóes sociais a partir de suas inumeráveis potencialidades.

Distante de uma infra-estrutura filosófica em sua produção discursiva, o conhecimento no âmbito dos estudos informacionais é visto como um processo técnico de dinamização de instrumentos de representação e fluxo da informação. Como nos releva Brookes (1980a), a Ciência da Informação se constrói ocupada em um oceano de aplicaçóes práticas do senso comum - aplicaçóes que envolvem cada vez mais o computador. Sua fundação, desta forma, descansa sobre o fundo falso de uma construção teórica - a "flutuação do limbo filosófico" no vocabulário brookesiano. Em outras palavras, a crise no regime epistemológico, vinculada à super-produção de registros dos saberes, assim como se deu no século XIII, levava à reestruturação da visão de mundo no âmbito da organização do conhecimento.

Assim, as bases ligadas à "explosão informacional”, à tecnologia da informação, a uma certa sociedade dita da informação, à emergência da interdisciplinaridade, indicam apenas um praticalismo fundacional, a resposta instantânea por uma demanda, não a construção filosófica profunda e permanentemente re-fundada. Como afirma Brookes (1980), a Ciência da Informação não apresentou, em seus mitos originais, uma fundação teórica. Como observarão Wersig \& Neveling (1975), diante do crescimento da complexidade de processos de comunicaçáo social e do desenvolvimento das tecnologias uma nova área é necessária para responder socialmente um novo conjunto de expectativas.

Ao longo dos anos que se seguiram à construção do neologismo "ciência da informação" alguns teóricos procurarão romper com este vazio teórico. Em Belkin \& Robertson (1976) teremos a noção de estrutura como uma categoria teórica do campo, antes de um conceito. Nessa visão, os diferentes usos do termo informaçáo ganham, nos estudos informacionais uma só característica generalizável: a idéia de que informação é estrutura que transforma a estrutura da mente. Todos os contextos - o da genética e o da sociedade - de uso da informaçáo podem, nesse enfoque, serem abordados a partir da categoria "estrutura" e seu desdobramento, "mudança de estrutura". Em Brookes (1980), encontraremos uma epistemologia objetiva para uma fundamentação teórica em Ciência da Informação, pois os artefatos do Mundo 3 popperiano, deixam de ser subjetivos e inacessíveis, ou seja, ao incorporarem em suportes de informação os saberes adquiridos, os cientistas são capazes de transmitir um conhecimento objetificado. 
O caminho para a análise objetiva da informação passa, por exemplo, pela exploração de técnicas quantitativas mais sensíveis, isto é, que permitem explorar de forma mais profunda os aspectos plurais das ciências sociais. De modo mais geral, passam pela necessária objetivaçáo. Esta pode ser representada socialmente pela necessidade de organizar o conjunto infinitamente heterogêneo de pontos de vista subjetivos através de leis e regras. Toda objetificação é um processo em curso, nunca completo. Assim, pois, ocorre com a quantificação objetiva - o uso prático de números para mensuração. Esse processo não é produto de uma epistemologia moderna, mas fruto de experiências que passam pelas civilizaçóes egípcia, indiana e chinesa, que pode ser verificada na Mesopotâmia e encontrada de forma desenvolvida entre os gregos. (BROOKES, 1980)

\section{Entre o maravilhoso informacional e o maravilhoso narrativo: as vias híbridas da complexidade na organizaçáo do conhecimento...}

A forma objetiva e aberta como tratamos a "explosão informacional", seja no discurso popular, seja no discurso científico no âmbito da Ciência da Informação, esconde os aspectos ligados à "fetichizaçáo" do conceito de informaçáo e, por vezes, a um posicionamento a-crítico diante de sua condição original - a condição de conceito.

Segundo Morrin (2007), o estudo do conhecimento atual não pode deixar de reconhecer sua complexidade. Esta complexidade diz respeito à noção de que o conhecer não pode ser reduzido a uma forma de visão de mundo - por exemplo, à visão teológica, ou à visão filosófica. Logo, o conhecer, em seu sentido complexo, é um caminhar pelo conjunto de elementos que costuram significados em torno dos mecanismos de apreensão da realidade.

Como nos revela Francelin (2003), os estudos que se orientam por um pensamento complexo partem do ponto de vista de que há fenômenos que não podem ser explicados com os instrumentos entáo convencionais. Em outras palavras, temos fenômenos que não são explicáveis com o conjunto de olhares da ciência moderna. Contudo, como visto, nossa objetificação da realidade parece definir um regime epistemológico refratário à complexidade. Ao conferir poder a partir da construçáo de discursos de verdade, para utilizar a expressão de Michel Foucault (2009), ordenamos nossa tradição discursiva em direção a uma categorização que trata o conhecer apenas como manifestação oriunda do informar.

Contudo, tanto no estudo do conhecer no século XIII quanto aquele do século $\mathrm{XX}$, percebemos que os graus de complexidade são múltiplos. Tomando como ponto de observação o ângulo social de análise, notamos que o conceito informação pode conduzir à redução da própria noção de complexidade, principalmente se tomamos os usos iniciais deste conceito no campo, quando estava estruturalmente ligado à manifestação física de sinais eletrônicos, pautados na formulação da Teoria Matemática da Comunicação de Shannon e Weaver. Para além desta observação, o que pensadores como Morrin (2007) nos chamam atenção está na recuperação de uma visão de mundo ampla, social e humana, estruturada no movimento humanista, que tem na escolástica suas primeiras sensibilidades, ainda que a historiografia procure tratar ambas as tradiçóes como contraponto - como observa Burke (2003), a maioria dos humanistas estudara nas universidades que criticava. 
Esta ciência para a informação apreendia o fenômeno social da informação como objeto científico - tendo o conceito de fenômeno social bastante próximo da teoria de Comte e Durkheim, de cunho positivista, preocupada com o controle/conquista de uma ordem natural, ou seja, o documento/livro e, por extensão, a informação, como entidades coisificadas. Neste contexto de concorrências e emergências, com uma sociedade burguesa plenamente estabelecida e uma sociedade científica socialmente legitimada, o estudo da narrativa é aparentemente deslocado - a narrativa é retirada da cena social como fonte de transmissão das tradiçóes e retirada da cena científica como fonte de conhecimento. No olhar foucaultiano (Foucault, 2002, p. 148), ocorre aqui a separação entre "palavra" e "ação" - o que Benjamin (1985), por sua vez, chamaria de fim da narrativa e nascimento da informação, e Chartier (2001), a "disputa” entre narrativa e conhecimento.

Com a breve descrição do conhecer no século XIII, percebemos, no entanto, como a informação registrada era causa e produto do conhecimento, assim como a Ciência da Informaçáo atualmente aponta, em seu olhar sobre o documento, como nos trabalhos de Hjorland (2000) e Frohmann (1999). Assim, se entendemos que no passado a narrativa se expressava como forma de conhecer - e base da complexidade do mundo - e a informação, no mundo contemporâneo, é tratada como nossa única forma de conhecer - nossa expressão "material" da complexidade -, reduzimos a realidade histórica a dois períodos entre mil anos que, na verdade, não apresentam, em seu cotidiano, tamanha cisão. Tratando a narrativa como conjunto de vozes que registra e transmite, de maneira subjetiva, os saberes acumulados pelas culturas, e a informação como elemento quantificável, que, do mesmo modo, registra e transmite, de maneira objetiva, os saberes acumulados, percebemos que tanto aquela como esta são fruto e semente, no medievo e na pós-modernidade, da complexidade; são semente e fruto, na pós-modernidade e no medievo, das operaçóes e mutaçóes do processo de conhecer.

\subsection{Nós cremos, nós vemos: o maravilhoso no medievo...}

Em determinados discursos historiográficos, identificamos a narrativa como modalidade de expressão e transmissão de saberes "deposta" pela informação. A partir da revolução dos suportes da informação, fundamentalmente a partir da explosão informacional gutenberguiana (Burke, 2002), passamos a tratar o acesso ao conhecimento como um processo de aquisição de informações. A informação, entidade objetiva, seria a unidade de representação e transmissão das culturas, atuando tanto quanto regulador de sistemas como fator de transformação social (Marteleto, 1987). De outro modo, a narrativa, povoada de ruídos - ou entraves para transmissão das mensagens -, seria tomada como matéria ausente do discurso sobre a aquisição do conhecimento na Ciência da Informação.

Como visto, imersa no imaginário da Idade Média, esta narrativa seria o modo fundamental de "conhecer" que perpassa os séculos até a Idade Moderna. Modo de conhecer fundamentalmente "poluído", no qual as mensagens viriam envolvidas em uma teia de visôes de mundo ligadas à teologia, à filosofia e às múltiplas práticas oriundas de um acusado "senso comum". Esta indústria de significados se confundia 
com os elementos que fariam o empirismo afastar, na modernidade, a relação entre objeto e observador, relaçáo estendida pelo positivismo dentro das ciências sociais e humanas.

A ausência de uma estrutura empírica no olhar científico dos séculos anteriores e a criticada intimidade entre objeto e observador levariam - ou tendiam a levar - até uma dessocialização dos objetos de pesquisa, afastando sua carga significativa e simbólica, fundamentalmente seu caráter maravilhoso, que o identificaria com os regimes epistemológicos da tradição medieval. Com o positivismo esta postura seria "contornada": as relaçôes sociais seriam coisificadas à moda dos objetos do mundo 1 de Popper, o das entidades físicas, e o observador se portaria apenas como um ente isolado do contexto de fundação e manifestação do objeto, como visto no trabalho de Brookes (1980). Ficavam assim negligenciadas todas as vozes que compunham os jogos narrativos que se multiplicavam no século XIX e XX, ligadas, por exemplo, a discursividade do mercado e de minorias culturais que ao longo dos séculos anteriores viriam reivindicar suas identidades, jogos expressos pelo maravilhoso informacional do século XX. O maravilhoso, no entanto, é apenas refletido no contexto do medievo, como agora observaremos.

Jacques Le Goff (1983), em seu estudo “O maravilhoso no ocidente medieval”, investiga a relação entre a noção de maravilhoso e os indivíduos no ocidente ao longo do medievo. Em seu trabalho, o historiador aproxima a idéia de maravilhoso aos termos que correspondem ao mesmo significado. Maravilhoso, segundo o conceito que aparecerá entre os séculos XII e XIII, significa, em linhas gerais, o plural do termo mirabilis, ou seja, mirabilia. Le Goff chama a atenção para o fato de que, onde percebemos, na linguagem contemporânea, uma categoria terminológica - o maravilhoso -, para os indivíduos do medievo este representava um conjunto de objetos. Para além de coisas "que o homem pode admirar com os olhos" (Le Goff, 1983, p. 20), o maravilhoso representa a coleção de manifestaçóes que provocam o olhar do observador.

No ocidente medieval, o historiador observa que o maravilhoso não representa um desenvolvimento obrigatório, mas é fruto do recolhimento e da recepção de "estratos antigos", ou seja, do "maravilhoso anterior". Neste aspecto, elementos maravilhosos dispersos nas crenças, nos textos e na hagiografia são recuperados a partir do século XII (Le Goff, 1983, p. 21). Le Goff (1983) indica ainda a relação de tolerância entre a Igreja e os limites do maravilhoso. O discurso teológico permitirá, de certo modo, o avanço do maravilhoso no início do duzentos - assim como vimos que a Igreja virá tolerar, em certa medida, o avanço de escolas "laicizadas" diante das movimentaçôes no regime epistemológico do medievo. Ali, segundo a reflexão do historiador, o maravilhoso já não era tão perigoso, imerso que estava na cultura laica. Por fim, temos, como terceiro elemento de discussão, o processo de "estetização" do maravilhoso, ou a construção de sua expressão imagética que permitiria adoração e culto.

Enquanto a igreja promovia, durante a alta Idade Média, entre os séculos $\mathrm{V}$ e XI, um controle sobre o maravilhoso, a partir da necessidade de ocultar elementos perigosos, este cerceamento cultural será diluído no correr do século XII, permitindo uma "irrupção do maravilhoso na cultura dos doutos" (Le Goff, 1983, p. 22). O romance de cavalaria, manifestação peculiar e identitária do período, fundar-se-á no discurso que se tece a partir de uma série de maravilhas. 
O maravilhoso tem como características fundamentais: a) o fato de ser produzido por forças sobrenaturais b) sua imprevisibilidade e c) sua aparição. Um conjunto de forças, por trás da coleção de objetos que se apresenta ao miraculoso, age de maneira a dar forma à expressão maravilhosa. No mundo cristão, o maravilhoso é expressado no milagre. Seria, o acontecimento milagroso, o maravilhoso "permitido", ou natural, ainda que oriundo de poderes sobrenaturais. O milagre como maravilhoso regimentado é o que o historiador abordará como racionalização das maravilhas. Esta regulamentação esvazia o maravilhoso, ao racionaliza-lo e afastá-lo de suas matérias fundamentais. $\mathrm{O}$ maravilhoso deixa, assim, de ser algo sobrenatural, ainda que de forças ocultas advenha; deixa, assim, de ser imprevisível, ainda que a previsibilidade de seu acontecimento não possa ser delineada. (Le Goff, 1983, p. 25)

Estas possíveis subversôes se dão, de fato, pois o autor do maravilhoso, Deus, ainda que oculto, é discursivamente determinado a partir de sua condição de ato puro. Se há Deus, existe regularidade, e o milagre, expressão do maravilhoso, ainda que misterioso e imprevisível, é paradoxalmente natural, e está determinado na regularidade divina. Assim, sua aparição é algo que está previsto. $O$ milagre se realiza através de intermediários, ou seja, através dos santos. (Le Goff, 1983, p. 25)

A funçáo do maravilhoso no cotidiano medieval expressa, assim, o "contrapeso à banalidade e à regularidade do quotidiano", apresenta-se como "forma de resistência à ideologia oficial”. Seres fabulosos se multiplicam e principia-se uma desumanização do universo, em direção a um mundo animalista. Recusa-se, assim, o humanismo, matéria do cristianismo medieval, ligado à idéia do homem feito à imagem de Deus. O indivíduo aqui é determinado pela sua aproximação aos animais, plantas e objetos. (Le Goff, 1985, p. 27)

\subsection{Foi quando nos pegamos a admirar: o maravilhoso na pós-modernidade...}

Como mencionado, ligada às recentes "explosōes informacionais" dos séculos XIX e XX, a Ciência da Informação percebe o conhecimento como um processo de apropriação objetiva de informaçôes. Como registra Marteleto (1997, p. 177), na pós-modernidade, "a própria natureza do conhecimento é então alterada, pois este não poderá passar pelos novos canais de comunicação e, portanto, tornar-se operacional, se não for traduzido em bits de informação", além de precisar ser transformado em mercadoria informacional, pela apropriação do mercado, que lhe confere os graus de verdade. No contexto pós-moderno, abordado temporalmente como fruto das transformaçôes no regime epistemológico de meados do século XX, não há uma revolução sumária, que anula todas as manifestações da história e inventa um novo modo de relação social. Ao contrário, através de um complexo jogo de assimilações, as relaçôes chamadas pós-modernas reinterpretam os gestos e movimentos anteriores, colocados, estes, sob e sobre diferentes ondas de uso e dispersão. As crenças, anteriormente pautadas nas escrituras sagradas, continuam pautando-se em escrituras - textos -, hoje dispersas por diferentes meios de inscrição, como a televisão, os portais on line, como também nos livros ditos científicos. A hagiografia é apenas substituída pela arqueologia biográfica dos ídolos midiáticos.

A morte de Deus anunciada por Nietschze define o século XX como o século pagão. Temos, desta maneira, a expressáo de um cotidiano secular ao longo do novecentos 
marcado por um retorno ao indivíduo afastado do discurso teológico, mas devoto do tecnológico. O paganismo informacional sugere o retorno ao maravilhoso, porém as maravilhas são representadas pelos conjuntos de objetos e serviços "inseridos" nestes objetos - os pacotes tecnológicos - de ordem tecno-comunicacional. No entanto, o maravilhoso, para além de uma categoria, também representa, no contexto contemporâneo, como no medievo, um conjunto de objetos, uma coleçáo de produtos e processos informatizados.

A informação se torna bem comum de diferentes saberes. No âmbito dos saberes chamados científicos, também ela ganhará status de objeto. Assim, a informação, enquanto maravilhoso do século XX, também se torna elemento do discurso dos "doutos". Cientistas e pesquisadores passam a estudar a informação em todas as suas "apariçôes", ou "epifanias" - vide o conceito de Borko (1968). Regimentar o milagre do aparecimento da informação é o labor deste personagem histórico. Sua prática retira da informação seus significados, a esvazia, tornando-a objeto, coisa. O romance e as narrativas fílmicas tratadas como o gênero da ficção científica serão as manifestações representativas desta condição, apresentando a série de maravilhas ofertadas pelas mutaçóes e pandemias tecno-informacionais.

Como Deus, a informação é, por vezes, tomada como ato puro. Ela está em todo lugar. Cabe ao pesquisador informacional defini-la, para dominá-la, materializá-la, para organizá-la, ainda que não queira retirar dela sua essência maravilhosa - sua condição de valor que substitui o trabalho como matéria de precificação da realidade. A informação está presente/ausente no jogo complexo da série de maravilhas que se iluminam a cada dia... a nova ferramenta de email, o novo celular, a nova câmera digital, seres fabulosos que levam o homem à sua comparação do humano com a máquina.

\section{Consideraçóes finais}

Assim como podemos perceber que o século XIII é um período de relação direta com o conhecimento registrado e pautado em uma estrutura objetiva, sendo o "complexo" o próprio registro da informação em si, aquém da própria condição do maravilhoso disperso nas narrativas, assim também percebemos que, no século XX, a informação é fruto de narrativas múltiplas e é cultuada, para além de sua suposta objetividade, como o resultado de uma série de "maravilhas". Logo, se enxergamos o maravilhoso e o informacional no medievo, também no mundo contemporâneo podemos perceber esta convivência. A informaçáo representaria o reflexo da complexidade no mundo contemporâneo. Em certa medida, assim como a narrativa do conto maravilhoso, a informação designaria a via contrária ao banal e ao regular no cotidiano. No entanto, neste âmbito, o homem é pautado em sua relação com a máquina. A desumanização se dá a partir das transformaçóes miraculosas da e para as tecnologias da informação. A série de produtos e serviços informacionais, observada em sua teia simbólica, que envolve mercado, sociedade, economia, etc., nada mais é que o conjunto de narrativas que recolocam o maravilhoso em nosso cotidiano.

Afora as características estruturais do maravilhoso no medievo, é também necessário, nos convoca Le Goff (1983, p. 27), um olhar social sobre o fato, ou seja, a construção diária do imaginário sobre o maravilhoso. Desta maneira, "o amplo alcance do 
maravilhoso medieval depende exactamente de um seu desenvolvimento interno, pelo qual o maravilhoso se estimula, se alarga e assume proporçóes ambiciosas e por vezes extravagantes". Em dadas circunstâncias, o maravilhoso é visto apenas a partir de sua condição primeira, sua sobrenaturalidade. No entanto, ele se revelará exatamente no seio de uma realidade. Assim também se dá com a informação. Por vezes as nuances de sua apresentação levantam um caráter miraculoso, o impossível. A ficção científica em sua expressão literária e fílmica antecipa e profetiza esta realidade. Por mais "improvável", o regime epistemológico informacional parece atualizar-se à medida que as novidades tecnológicas arrancam suspiros de admiração dos incrédulos. As maravilhas anunciadas em serviços e produtos como orkut, blog, twiter sáo expressóes do maravilhoso informacional.

Ao conceber, de forma rasa, a Idade Média como campo marcado pelo domínio religioso percebemos como negligenciamos o processo de formação do conhecimento e reduzimos nosso reconhecimento da complexidade deste período. Por outro lado, tendemos a definir, principalmente a partir do positivismo na epistemologia da Ciência da Informação, a informação como fonte de domínio do mercado, tendendo a rejeitar as outras formas de produção de saberes, e fundar a complexidade nas transformaçóes tecnológicas. $\mathrm{O}$ conhecimento objetivo, como marca identitária da informação, seria a única expressão do regime epistemológico no contexto da pós-modernidade. Sabemos, no entanto, que ambos os períodos escondem e relevam contingências que redistribuem estas expressôes, demonstrando a forma como ambas, narrativa e informação, lá e aqui, não apenas coexistem, como se entrelaçam em um hibridismo que é fonte, também ele, de complexidade e desafio ao conhecer.

\section{Referências bibliográficas}

Belkin, N.J.; Robertson, S.E. (1976). Information science and the phenomenon of information. Journal of the American Society for Information Science, jul/aug. 197-204.

Benjamin, W. (1985). Narrador; consideraçôes sobre a obra de Nikolai Leskov. In: Benjamin, W. Magia e técnica, arte e politica: ensaios sobre literatura e história da cultra. Obras escolhidas; v. 1. São Paulo: Brasiliense.

Boni, L.A. (2000). Prefácio. In: ULLMANN, Reinholdo A. A universidade medieval. (2a. ed). Porto Alegre: EDIPUCRS.

Borko, H. (1968). Information science: what is it?. American Documentation, 19, 1, 3-5.

Boyce, B.R.; Kraft, D.H. (1985). Principles and theories in information science. Annual review of information science and technology (ARIST), 20, 153-178.

Brookes, B.C. (1980). The foundations of information science. Part I. Philosophical aspects. Journal of Information Science, 2, p. 125-133.

Burke, P. (2002). Os problemas causados por Gutemberg: a explosão da informação nos primórdios da Europa moderna. Estudos Avançados, São Paulo, 16, 44, 173-185.

Burke, P. (2003). Uma história social do conhecimento: de Gutenberg a Diderot. Rio de Janeiro: Jorge Zahar.

Chartier, Rr. (2001). Uma crise da história? A história entre a narração e o conhecimento. In: PESAVENTO, S. J. Fronteiras do milênio. Porto Alegre: Universidade UFRGS. 115-140. 
Foucault, Ml. (2002). As palavras e as coisas: uma arqueologia das ciências humanas. Tradução Salma Tannus Muchail. ( $8^{a}$ ed). Martins Fontes: Sáo Paulo.

Foucault, Michel. (2009). A ordem do discurso. São Paulo: Loyola.

Francelin, M.M. (2003). A epistemologia da complexidade e a ciência da informação. Ci. Inf., Brasília, 32, 2, 64-68.

Frohmann, B. (1992). The power of images: a discourse of images: a discourse analysis of cognitive viewpoint. Journal of Documentation, 48, 4, p. 365-386.

Frohmann, B. (2009). Revisiting "what is a document? Journal of Documentation, 65, 2, 291-303.

Ghisalberti, A. (2001). As raizes medievais do pensamento moderno. Porto Alegre: EDIPUCRS.

Hjorland, B. (2000). Documents, memory instituitions and information science. Journal of Documentation, 56, 1, 27-41.

Le Goff, J. (1983). O maravilhoso e o quotidiano no ocidente medieval. Lisboa: Ediçôes 70.

Marteleto, R.M. (1987). Informação: elemento regulador dos sistemas, fator de mudança social ou fenômeno pós-moderno?. Ciência da Informação, Brasília, 16, 2, 169-180.

Morin, E. (2007) Ciência com consciência. (10 ed). Rio de Janeiro: Bertrand Brasil.

Pinheiro, L.V.R. (2002). Gênese da Ciência da Informação ou sinais anunciadores da nova área. In: AQUINO, M. de A. (org.). O campo da ciência da informação: gênese, conexôes e especificidades. João Pessoa: Ed. Universitária, 61-86.

Silva, A.M. da; Ribeiro, F. (2002). Das ciências documentais à ciência da informação: ensaio epistemológico para um novo modelo curricular. Porto: ediçôes Afrontamento.

Ullmann, R.A. (2000). A universidade medieval. (2a. ed). Porto Alegre: EDIPUCRS.

Verger, J. (2001). Cultura, ensino e sociedade no ocidente nos séculos XII e XIII. Bauru: EDUSC.

Shera, J.H.; Cleveland, D.B. (1977). History and foundations of information science. Annual review of information science and technology (ARIST), 12, 249-275.

Wersig, G.; Nevelling, U. (1975). The phenomena of interest to Information Science. The information scientist, 9, 4, 127-140. 